\title{
School-based Support Teams as Communities of Enquiry: A Case of Developing Inclusive Practices in the Free State Province of South Africa
}

\author{
T.M. Makoelle \\ Department of Educational Psychology, University of Johannesburg, South Africa \\ E-mail: tmakoelle@uj.ac.za
}

KEYWORDS Reflection. Inclusion. Case Study. Collaboration

\begin{abstract}
School-Based Support Teams were established by the South African National Department of Education in schools to deal with inclusive education and its implementation at school level. The role of these teams include, among others, organising support and establishing the individualised education programmes for vulnerable and learners perceived to be having barriers to learning. However these teams also have to be instrumental, engage, reflect and probe and enquire about the inclusive pedagogic practices in order to develop and enhance their use in the classrooms. This paper therefore analyses the role of the School-Based Support Teams (SBST) in relation to the development of inclusive practices. The study was a case study within qualitative action research design. Data was analysed using an inductive analytical framework and group interpretative data analysis method. Among the findings of the study is that South African teachers are less critical, reflective and collaborative and there is a need to transform the SBSTs to be communities of enquiry which will on the continuous bases probe, critique, and reflect practice in order to improve and develop inclusive practices.
\end{abstract}

\section{INTRODUCTION}

The inclusive education model of South Africa has been underpinned by the Constitution of the country (RSA 1996) since the dawn of the new political dispensation, which seeks to transform the society from an uninclusive to an inclusive one. The constitutional principles on basic rights embrace all initiatives for building an inclusive model of education. Section $9(3,4,5)$ of chapter 1 of the Constitution (RSA 1996) clearly articulates the notions of non-discrimination, and of providing education in the language of the learner's choice which are fundamental to the notion of an inclusive society (Pillay and Di Terlizzi 2009). Acknowledging the significance of the Constitution, the national education department embarked on a legislative path which sought to ensure the realisation of constitutional modalities to encrypt the philosophy of inclusion. The introduction of the South African Schools'Act 84 of 1996 (SASA) (RSA 1996), then later the White Paper 6 (DoE 2001), acted as a legislative and policy framework for the implementation of inclusive education. Section 5 (1) of SASA (RSA 1996) states: "A public school must admit learners and serve their educational requirement without unfairly discriminating in any way"
The policy development process which culminated in White Paper 6, became the roadmap for transforming the education system towards a more inclusive one (Walton et al. 2009). The White Paper outlined the model of inclusive education aimed at responding to learner and teacher needs by establishing institutions and structures of support which will ensure quality education for all. The following organogram illustrates the relationship between the support structures enhancing inclusion within the South African education system (see Fig.1)

The model of an inclusive education system as indicated above evolved from the previously mentioned constitutional parameters, and its mandate is being carried forward by the national department of education, provincial departments, education districts schools and institutions of learning, such as adult basic education and training centres (ABET). The principles of expanding access of education to all are crucial for: ensuring inclusive policies; ensuring change and upgrading of infrastructure; enhancing institutional support and development and ensuring the equitable distribution and use of educational resources (DoE 2001). While the structures outlined in the diagram focused on inclusion of the whole system, the focus in this paper is on the role of inclusive structures within a school and how this impacts on inclusive practices. 


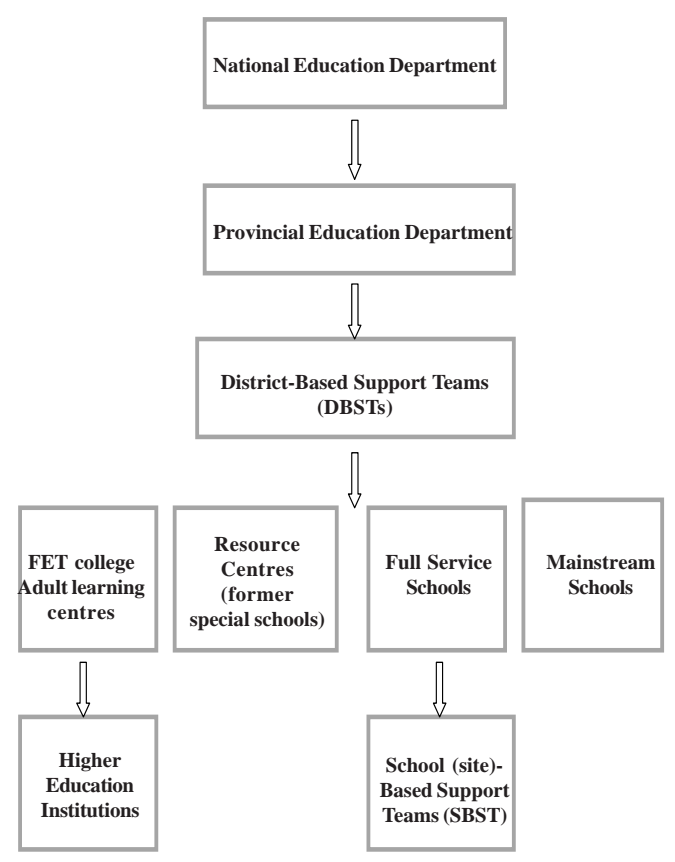

Fig. 1. Organogram of the South African education system

The School-based Support Teams (SBSTs) were established by all institutions. These teams comprised teachers, special needs teachers, care staff, learners, parent care givers, members of district-based support team, and local community members. A SBST coordinates the institutional support of the institution, identifies institutional needs, collectively develops strategies to address needs and barriers to learning, monitors the availability and use of resources, and assesses the general operation of an institution in terms of inclusion (DoE 2001).

\section{Problem Statement and Aim of the Study}

These committees are supposed to be central to developing inclusive practices; however, the researcher's observation is that they seldom reflect on practices but are mostly concerned with the identification of learners with special needs and their role is predominantly referrals. Further, the focus is always on diagnosing the learner for barriers rather than assessing the relevance of educational structures and pedagogic practices to addressing the specific barrier. Therefore the following overarching research question was asked:
Do SBSTs develop practices of inclusion in their schools?

In order to answer this question the following sub-questions were posed:

- To what extent do SBSTs collaborate, reflect, critique current pedagogic practices in relation to inclusion?

- To what extend are they involved in development of inclusive practices?

- How can SBSTs be assisted in improving their skills in the development of inclusive practices?

\section{Conceptualizing a Community of Enquiry}

Firstly, the researcher proceeded from the premise that critical reflection on practice thrives if there is collaboration among practitioners; therefore, the formation of collaborative communities with a shared goal to improve their practice is crucial. Retallick et al. (1999) describe a community as a social organisation which is characterised by relationships and the sharing of ideas (Dunlop et al. 2011). It is a body that binds people together to a set of values and ideas.

Practitioners are afforded the opportunity to interact with one another, reflect on their practice, and begin to change their attitudes and beliefs towards an inclusive teaching practice (Makoelle 2012). Not all communities are engaged in action learning, which is learning through collaboration by members of a team. The reason is that, for such learning to take place, a community of enquiry must be developed. Such a community is therefore defined as a group of practitioners who share a common practice through a set of agreed values, knowledge, terminology and procedures, which offers scope for problem-solving (Aubusson et al. 2012; Reason and Bradbury 2006). The purpose of such a community is to create knowledge and clarify their perceptions of reality, goals and strategies for achieving them. Data are collected for the purpose of solving their immediate problems by building local theory, testing it through action by inferring from the observable behaviour in order to institute change.

The role of the researcher is to create conditions under which practitioners can test theories of practice for the purpose of learning (Reason and Bradbury 2006). The process by which practitioners probe their practice occurs within 
a community of enquiry. According to Retallic et al. (1999) echoed by Green et al. (2012), the community of enquiry is referred to as a community of learning bearing similar attributes such as collaboration, engagement, reflection and the development of the local theory that addresses a problem as identified by the practitioners. The community of enquiry embarks on the process of testing their local theories. The process of testing local theories as discussed here was borrowed from Reason and Bradbury (2006) because of its direct relevance to this study. Therefore, the following discussion will deal with how theories are tested through the use of questions and the determination of patterns from data during process of analysis.

\section{The Manner in Which Theories are Tested}

The community of enquiry is a collective intended to probe the prevailing practice by asking the following questions (Reason and Bradbury 2006: 133):

- How do practitioners perceive a situation or problem?

- What results do they wish to achieve?

- What strategies do they intend to use in order to achieve these objectives?

- What were the actual outcomes of these strategies?

- To what extent did the outcomes match the intended results?

The above-mentioned questions are significant for the process of enquiry. The community of enquiry determines patterns from the data through the use of an interpretive process by

- looking at multiple interpretations of data (inter-subjective testing);

- making comparisons between what teachers say they do (espoused theory) and what was observed (theory in use);

- reflecting critically, using the "ladder of inference", which is the interpretation of data from a concrete to a more abstract level of reasoning - that is, if no consensus can be reached, practitioners could descend to a concrete level to identify an area of divergent thinking.

As the interpretive process does not always guarantee consensus, the testing of a theory adopts the principle of the falsifiability of the theory. This process provides alternative solutions by suggesting a change of beliefs, percep- tions and practice to inform transformation (Reason and Bradbury 2006). The authors further posit that change will take place at two levels, namely at the level of strategies (single loop) and at the level of conditions (double loop). Change at the level of strategies is often easy whereas change at the level of conditions is complicated because it involves changing assumptions, goals, values and beliefs. When the community of enquiry is probing practice, reflecting on it and drawing conclusions, action learning takes place because the group learn through the experiences of their actions (Brockbank and Macgill 2004). The process of learning collaboratively as a community is important for empowering the practitioners and increasing their participation (Truman et al. 2000).

The researcher therefore asserted that communities of enquiry must engage in some form of action research and, consequently, action learning to improve their practice. In this study, the researcher adopted a two-dimensional approach to the study: firstly, a critical collaborative form of action research through which the participants critically reflected on their practice in order to enhance an inclusive pedagogy and, secondly, a case study approach wherein inclusive practices are developed.

\section{METHODOLOGY}

Action research is a complex process that recognises the role of the teacher as researcher, but differs in terms of the form of the involvement and participation of subjects. The form of action research that was adopted in this study was Collaborative Action Research (CAR).CAR is a research process led by the subjects of research (teachers) collaborating with the researcher. For example, Mohr et al. (2004) acknowledges that this kind of action research is a method of research managed by teachers who elect their own research group, which contributes to the planning and monitoring of data collection and analysis processes of research (Makoelle in Francis et al. 2010). It is transformative in nature and offers teachers the opportunity to collaborate (Aldridge et al. 2012). Teachers taking part in action research should have certain characteristics and behave in a particular manner; for example, Pollard (2002: 41) postulates that teachers should have the following characteristics in mapping the development through action research: 
- the systematic questioning of their own practice as a basis for development;

- commitment to study their own practice;

- the ability to test a theory in practice (which happens when teachers have a strong network).

The network between teachers manifests itself in what is called a "research forum", which is a platform created to deal with conclusions, critique and test new ideas (Pollard 2002). Research is mostly public in that stakeholders reflect on their practices publicly through the analysis of data and evidence collected - what Ainscow et al. (2006) refer to as group interpretive process (Makoelle 2012). Through evidencebased data, teachers begin to improve on their practice - a phenomenon referred to as "evidence-based teaching” (Hammersley 2007).

On the same note, Altrichter and Elliott (2003) mention that during the action research process teachers assume what is called a "double task"; that is, the role of teacher and researcher. Teachers practice and reflect on their practice using action research either with themselves or with colleagues through a process that Posch (1996: 43) calls "dynamic networking”. The process of action research is characterised by the process of linking theory with practice, maintaining the conceptual and perceptual knowledge, value objectivity and subjectivity of the research and focusing on the individual or group (Altrichter and Elliott 2003).

The process is thus teacher-driven and management of the school should not dominate the process. Hence Fullan (2001) and Somekh (2006) caution against management-led whole-school action research, which is intent on disguising teacher involvement while imposing ideas on teachers. In this study, my position as principal posed this dilemma; however, the organisation of the process of inquiry was such that teachers took initiative in probing their practice, although there were instances where teachers requested my input and guidance.

Unlike in management-led whole-school action research, teachers negotiate and agree on the research questions and the means to find answers to them. Action research adopts an emancipatory approach by looking critically at power relations and engaging with the broader political structures to ensure social justice (Tinning 2012). Somekh (2006) - drawing on Habermas's concept of “communicative action”,
Marx`s concept of "false consciousness" and Foucault's "deconstruction of the regimes of truths" - supports the argument that action research attempts to emancipate the socially oppressed through the deconstruction of meaning through the participation and involvement of teachers as researchers. In order to achieve this objective, we challenged our beliefs and thoughts and also where these were coming from, for example, our past experiences and how they were influencing our current thinking and practice. It follows that the process of action research is driven by teachers forming networks and contributing through collaboration to learn more about their practices. However, Ainscow et al. (2006) caution against regarding the contribution of practitioners as being above critique. They suggest that the action research process should not lose its element of being reflective and critical, and that to strengthen the outcomes of the process, the voices of the practitioners must be supported by providing research training as well as different theoretical perspectives to clarify the views of the practitioner.

Action research has high triangulation potential as different sources of data are collected during the process; for example, Ainscow et al. (2006) describe this form of research as a process whereby teacher researchers engage in processes of triangulation such as observation, interviews, pictures and videos. The process of data analysis and interpretation varies according to the interests of the researchers. The notion of a group-interpretive process, which is the process of teachers collaboratively embarking on reflection and meaning-making, becomes crucial in the interpretation of data (Somerkh 2006). The process is illustrated by Kemmis and McTaggart (1988), for example, by means of a four-phase model:

- The Plan: a flexible, unpredictable anticipation of what will occur in the future;

- The Action: a deliberate and controlled activity process often defined by putting ideas into action, as influenced by past practices and critical reflection on the changes between past and new practices;

- Observation: documenting and recording the effects of action in an open way in addition to recording the unexpected, using mostly research diaries;

- Reflection: recall of action as observed, active engagement with data to make sense of 
it by giving meaning to it and interpreting the data, which is evaluative in nature.

The above model stages were adopted in this study. Action research started by establishment of the community of enquiry. The community then determine the objectives of the group. The action research process started by the community of enquiry identifying the problem with their current practice. The group unanimously agreed in the three research questions as objectives;

To what extent do we collaborate, reflect, critique current pedagogic practices in relation to inclusion?

To what extend are we involved in the development of inclusive practices?

How can we improve our skills in the development of inclusive practices?

The action research took place in stages, firstly during the planning stage the group sort to determine the level of our collaboration, reflection and being critical about their activities towards the development of inclusive practices at our school. Secondly the group analysed the extent to which SBST members were involved in processes of developing inclusive practices. Lastly after reflections about the above the group sort to suggest the different ways by which the research team can improve their skills in developing practices of inclusion in own context.

\section{The Case Study in Action Research}

In this study, apart from the action-research project designed to enable the participating teachers to address the shortcomings of their pedagogy with respect to inclusion, the researcher decided to conduct a case study investigation within the theoretical schema of action research. This was a meta-research investigation into a case of change in a South African school. But, firstly, for the purposes of clarifying the researchers' stance, a case is conceptualized from the perspective of Denzin and Lincoln (2003, 2005: 442) who posit: "The case is not a methodology but a choice of what is to be studied." This definition is also supported by Scott and Usher (1999).

Most of the literature on educational case studies indicates that it is one of the more widely used approaches in qualitative research. There are various types of cases, ranging from single (when a single case is intensively studied) to multiple (when numerous cases are studied). The choice of a case is usually determined by the nature of the phenomenon under study and the research questions the researcher intends to find answers to (Yin 2012; Dul and Hak 2012). An intrinsic case study is conducted when a better understanding of the phenomenon under study is needed; multiple case studies give a thick description of many cases, often with the purpose of generalising for the population of cases; whereas an instrumental case study is focused on gaining more insight which could serve the secondary purpose of clarifying the knowledge about the case under study (Denzin and Lincoln 2005). Although the researcher is guided by the research questions in order to determine which data to collect from the case, case-study research data are mostly not aimed at making generalisations but at achieving a detailed description of the case. Denzin and Lincoln (2005: 445) mention the following aspects as being prominent in case studies:

- the nature of the case;

- the historical background to the case;

- the context in which it is found (political or economic);

- its physical setting;

- other cases with which it could be compared;

- the informants through which it could be known.

Cases are often chosen for their representativeness and relevance to what ought to be studied. They could be seen as typical (representing other cases) or atypical, which means not necessarily common to others. Selection of a single case is done when clear, well-rounded propositions have been made and the case meets all the requirements of the study (deVous 2001). Merriam (1998) postulates that case studies are not focused on the outcome but designed to obtain a rich data description of the case. They are context-bound, not variable-bound, and they are aimed at making discoveries rather than achieving confirmation.

For instance, Edge (2001: 1) argues that "case studies constitute a public recognition of the value of teachers' reflection on their practice and constitute a new form of teacher research". The case study could be a tool for reflecting on detailed processes of teaching practice. Conversely, Comm et al. (2000) indicate that case-study research has disadvantages such as a lack of generalisability and the difficulty of finding causal relationships between variables. However, case-study research according to Edge 2001: 34) is known to have the following advantages:

- It takes the researcher to the real-life situation. 
- It affords the researcher the chance to see things through the eyes of the participant.

- The researcher gains direct experience of the phenomenon under study.

In support of the use of case studies, Weber (2007) justifies the use of case-study research in the educational context of South Africa by indicating that, unlike in the past when teachers had had policies imposed upon them and were never given a chance to air their views, action research offers an ideal opportunity for researchers to gather rich data. In this study the use of a case study is contextualised within the framework of action research. The following section therefore describes the case. Golden High School (pseudonym) in the Free State province of South Africa was chosen for the following reasons:

- For developmental reasons, the school is serving a previously disadvantaged community.

- The school is where the researcher was principal, which made it easily accessible.

- The school is one of the models of the new South Africa.

- It has the features of both a previously disadvantaged and advantaged school.

- It is highly performing in terms of matriculation results and reflects the demographics of the country.

- Because of the school's relevance to the new educational dispensation, the research results would be easily transferable to other schools.

Fifteen teachers at Golden High school voluntarily took part in the project. The sample of 15 teachers was spread as follows: junior teachers (0-10 years of teaching experience); specialist teachers (10-20 years of teaching experience); and senior specialists (20 and more years of teaching experience). This was drawn from the population of 30 teachers.

The Representative Council of Learners (RCL) - a body of 20 democratically elected learners representative of all the grades at the school and mandated to look at matters of learner interest - took part from the learners' perspective as a focus group.

\section{Data Collection and Analysis of Data}

Data were collected during the action research process. Data were collected for the two research processes, namely action research (with teachers) and case study (researcher). While there are many ways of collecting qualitative data, during action-research process the researcher and the community of enquiry regarded the following methods as relevant and appropriate: observation, interviews and group reflective meetings. Because data were collected for the action research process and for the case study, it was important to provide details of who did what before data-collection techniques could be discussed. The following table therefore summarises the data-collection techniques used in this research (see Table 1).

Table 1: Summary of research techniques

\begin{tabular}{ll}
\hline $\begin{array}{l}\text { Data collection } \\
\text { technique }\end{array}$ & Who \\
\hline Observation & $\begin{array}{c}\text { Both researcher and the teachers } \\
\text { engaged in observations } \\
\text { Researcher interviewed SBST } \\
\text { Interviews }\end{array}$ \\
$\begin{array}{l}\text { Group reflective } \\
\text { meetings }\end{array}$ & $\begin{array}{c}\text { Bothe teachers and researcher } \\
\text { held rective meetings }\end{array}$ \\
\hline
\end{tabular}

The data analysis took place at two levels, namely during action research through group interpretive process, and for the case study metaresearch process. The data were collected, processed and analysed systematically. The dataanalysis process is always preceded by datamanagement processes as large quantities of data could be generated by means of qualitative research.

Firstly, data analysis means that, after collection, the must be processed and meaning must be attached to it. For group interpretative analysis process data was analysed during interpretative meetings held after each action research stage. The meeting took a form of discussion and the minutes of all the meetings were taken by the researcher as the secretary of the community of enquiry and afterwards verified by all the other members to check if they were a true reflection of the deliberations. The interpretative discussions were chaired by an elected chairperson for the meeting. The discussions were facilitated by asking questions to stimulate discussion. The group firstly read the data, determined themes, assigned extracts (quotations) to the themes and then derived interpretations. Agreements on interpretations were reached through consensus. The dissenting views were discussed at length and recorded as such. The analysis of data collected for the case study was analysed using an inductive analysis framework. In analysing the narratives the following steps were followed: (Laws et al. 2003: 395):

Step 1: Reading and rereading all the collected data: The purpose of reading the data closely 
was to ensure that the researcher was fully conversant with it, thus making the process of analysis more manageable.

Step 2: Making a preliminary list of themes arising from the data: themes were then derived from the data to make it more manageable.

Step 3: Reading the data again to confirm the themes: reading the data several times, the researcher was able to verify that the interpretations were correct.

Step 4: Linking the themes to quotations and notes: the researcher then wrote themes alongside the quotations and notes as I went through the data.

Step 5: Looking through the categories of themes to give an interpretation(s): In the course of analysing the data, the researcher attempted to answer the research questions.

Step 6: Designing a tool to assist in discerning patterns in the data

In order to triangulate and determine the patterns during data analysis, a spreadsheet was used which gave a summary of the themes. For example, the spreadsheet recorded the title of the theme and quotations from different sets of data.

Step 7: Interpreting the data and deriving meaning: During this stage, the researcher read the quotations and derived the meanings they were indicating in relation to each of them. This resulted in my interpretations, which the researcher presented according to each theme.

\section{RESULTS}

Data harvested from the four action research stages was analysed. The analysis yielded the following themes: SBST and collaboration, SBST and being critical, SBST and reflection, SBST and development of inclusive practices and SBST beliefs and attitudes. The themes are presented in such way that they address the objectives of the research group and answers the research questions:

\section{To What Extent Do We Collaborate, Reflect, Critique Current Pedagogic Practices in Relation to Inclusion?}

\section{Theme: SBST and Collaboration}

There analysis of data revealed that the SBST members were less collaborative with regard to the development of inclusive practices. For in- stance the emphasis seemed to be on the administrative roles of the committee rather those on inclusive practices. To support this asked if collaboration was necessary to develop practices of inclusion one group member said "every teacher practice inclusion his/her own way so there is no need to look at what others are doing" The implication is that less collaborations affects negatively the potential for testing different inclusive practices.

\section{Theme: SBST and Being Critical}

There was a tendency to adopt practices developed elsewhere without critically evaluating their applicability within both the school and cultural context of the learners. Training by the SBST members of their staff seemed canonical, in the sense that guides and manuals from the department of education as well as non-governmental organisations were followed to the latter. One of the group members said "we follow the departmental guidelines in teaching in an inclusive way, methods and strategies in the guideline documents are used" This indicate that by not being continuously critical about once practice limit the chances of evaluating how inclusive the practice is.

\section{Theme: SBST and Reflection}

There SBST seemed not to be engaging in critical reflection about practices that are prevalent in the school and assess how those addresses the needs of learners in the school context. The situation is such that the SBST seldom reflected with teachers about their practice in the classroom, all processes are left to individual teachers. One of the group member alluded “ we do not engage as a group in reflection, maybe we do as individuals" Less reflection by teachers minimise the ability to identify areas of development in their practice which is significant in evaluating their inclusivity.

\section{To What Extend Are We Involved in the Development of Inclusive Practices?}

\section{Theme: SBST and Development of Inclusive Practices}

The indication was that the SBST did not think the development of inclusive practices fell 
within the scope of their responsibility. The practices were perceived to be aspects that should be developed by experts and officials from the department of education. For example one group member said" We can't develop own practices because there are experts at district offices who are better places to do that" The non-participation of teachers in the development of inclusive practices seem to limit their chances of developing practices that are relevant to their context.

\section{Theme: SBST Beliefs and Attitudes}

The beliefs and attitudes of group members seemed to indicate that inclusive practices were only geared towards learners with disability and the understanding was to accommodate such students in the mainstream classrooms. For instance this quote provided evidence "our focus is how do we include learners with disability in our teaching and in the classroom" The beliefs and attitudes of teachers hampered their understanding of what it means to include all learners, thus influencing the implementation of inclusion negatively.

\section{How Can We Improve Our Skills in the Development of Inclusive Practices?}

The analysis of data from the reflective meetings indicated that there was a need for the SBST to collaborate, be critical and reflective about the practices of inclusion the school. This was attested by this quote from one of the group members "we have learned from this process that our role does not only lay in the administrative duties of the SBST but also in probing and asking questions about our current practices” The implication was that for the development of inclusive practices collaboration and critical reflection on practice seemed very essential.

The analysis revealed that there was a strong inclination among the group members that a community of enquiry created a good platform for engagement and constructive contribution to inclusive practices in their school context. For example one of them posited: I think we are now aware that our role goes beyond just being a welfare committee but we can make valuable inputs into appropriate and relevant inclusive practices in our school situation, those that will work in our context" The implication is that forming communities of enquiry could be beneficial for the development of inclusive practices.
There was also a strong indication that the community of enquiry provided space for SBST to confront their beliefs and attitudes about inclusive practices, for instance one member postulated "we were able to challenge the way we think about inclusion and how we can make it practical in our own school" The community of enquiry seems to create a way in which change can be facilitated especially in developing inclusive teaching and learning environments.

\section{DISCUSSION}

The finding of this study indicate that for SBST to make a significant contribution to the development of inclusive practices, they have to collaborate, be critical and reflect more about the state of the current inclusive practices in their own school context (Ainscow et al. 2006). This can take place when SBSTs act more as communities of enquiry rather than mere administrative committees (Reason and Bradbury 2006). Further there is a need for SBST to be highly involved in the development of inclusive practices rather than focus on adopting alien practices in their school without questioning their validity in terms of their situation and context (Makoelle 2012).

The study also pointed out that there is a need to transform SBSTs to be communities of enquiry, in that their scope of operation is extended to include that of reviewing, critiquing the current practices and making recommendations about what out to be happening as far as inclusive pedagogy is concerned in their own school context which is currently not captured in the policy guidelines of White Paper 6 (DoE 2001).

With regard to developing inclusive practices, firstly, the use of action research through the development of communities of practice (research teams), as constituted in this study, their establishment and the manner in which these kind of community of enquiry was used to enhance the development of inclusive practices in this study seemed pivotal (Makoelle 2012).

While the South African literature on inclusive practice has indicated that School-Based Support Teams (SBSTs) have been established in schools to deal with the implementation and handling of inclusive education (DoE 2001), the study has demonstrated that they do not seem to create 
a platform where teachers can share their views on teaching methodology in an inclusive educational environment in particular. The SBSTs are focused mostly on the technical aspects of inclusion, with much less emphasis on teaching methodology. From time to time, teachers have to do research to investigate new ways of enhancing inclusion. Teachers can only do this by establishing communities of enquiry within which they try out new methods. Schools establish communities of enquiry which will conduct research according to local contexts and are teacher driven (Somekh 2006). These research communities will then empower teachers with regard to the development of inclusive practices.

\section{CONCLUSION}

The indication is that while SBSTs have been established to deal with the implementation of inclusive education at school level, they are still far from changing the exclusive conditions of pedagogy which are inherent of the past practices of the exclusive education dispensation of the past. This study has constituted the first step in the transformation of SBSTs into communities of enquiry that would collaborate to probe, reflect and critique the current practices and develop those practices that would enhance inclusion.

\section{RECOMMENDATIONS}

Based on the findings of this study I therefore recommend that schools establish within SBSTs communities of enquiry which are composed of mainly teachers. While it could be advantageous to have experts on the inclusiveeducation research teams, it is recommended that these communities of enquiry be run and controlled by teachers themselves. The role of experts should be to advise, not to play a leading role. Communities of enquiry should function in such a manner that teachers collaborate, critique their practice and learn from one another. The following could be the main questions for teachers to follow in pursuing the process of enquiry:

- How inclusive is current teaching practice?

- Which practices are relevant to school context?

- What strategies to use in order to make practice more inclusive?
These questions could be used to provide an opportunity for teachers to probe, critique and reflect about their practice. Trying alternative practices to enhance inclusivity in their practice could have positive effect on their beliefs and attitudes towards inclusion.

\section{REFERENCES}

Ainscow M, Booth T, Dyson A 2006. Improving Schools: Developing Inclusion. London: Rutledge. Aldridge J M, Fraser B J, Bell L, Dorman J 2012. Using a new learning environment questionnaire for reflection in teacher action research. Journal of Science Teacher Education, 1-32.

Altrichter H, Elliot J 2003. Images of Educational Change. Buckingham: Open University Press.

Aubusson P, Ewing R, Hoban G 2012. Action Learning in Schools: Reframing Teachers' Professional Learning and Development. London: Routledge.

Brockbank A, Mac Gill I 2004. The Action Learning Handbook: Powerful Techniques for Education, Professional Development and Training. London: Routledge Falmer.

Comm R, Hammersley M, Foster P 2000. Case Study Method. London. Sage Publications.

Department of Education 2001. Education White Paper 6, Building an Inclusive Education and Training and System: Department of Education.

Denzin NK, Lincoln YS 2003. Strategies of Qualitative Enquiry. London: Sage Publications.

Denzin NK, Lincoln YS 2005. The Sage Handbook of Qualitative Research. $3^{\text {rd }}$ Edition. London: Sage Publications.

deVous D 2001. Research Design in Social Research. London: Sage Publications.

Dul J, Hak T 2012. Case Study Methodology in Business Research. London: Routledge.

Dunlop L, Humes G, Clarke L, Martin VM 2011. Developing communities of enquiry: Dealing with social and ethical issues in science at key stage 3. School Science Review, 93(342): 113-120.

Edge J 2001. Action Research. Virginia: Jill Burton.

Francis D, Mahlomaholo S and Nkoane M 2010. Praxis towards Sustainable Empowering Learning Environments in South Africa. Bloemfontein: Sun Press.

Fullan M 2001. The New Meaning of Educational Change. ${ }^{\text {rd }}$ Ediition. London: Routledge Falmer.

Green L, Condy J, Chigona A 2012. Developing the language of thinking within a classroom community of enquiry: Re-service teachers' experiences. South African Journal of Education, 32: 313-330.

Hammersley M 2007. Educational Research and Evidence-based Practice. London: Sage Publications.

Kemmis S, McTaggart R 1998. The Action Research Planner. $3^{\text {rd }}$ Edition. Victoria: Diakin University.

Laws S, Harper C, Marcus R 2003. Research for Development. London: Sage.

Makoelle TM 2012. Analysing the use of action research to develop practices of inclusion: A case of a South African School. Journal of Sociology and Social Anthropology, 3(2): 83-91. 
Makoelle TM 2012. The state of inclusive pedagogy in South Africa: A literature review. Journal of Sociology and Social Anthropology, 3(2): 93-102.

Merriam SB 1998. Qualitative Research and Case Study Applications in Education. San Francisco: Josseybass Publishers.

Mohr MM, Roger C, Sanford B, Nicerino MA, Maclean MS, Clawson S 2004. Teacher Research for Better Schools. New York: Teacher College Press.

Pillay J, Terlizzi MD 2009. A case study of learner's transition from mainstream schooling to a school for learners with special educational needs (LSEN) lessons for the mainstream education. South African Journal of Education, 29: 491-509.

Pollard A 2002. Reading for Reflective Teaching. London: Continuum.

Posch P 1996. The ecologisation of schools and its implications for educational policy. Cambridge Journal of Education, 29(3): 341-348.

Reason P, Bradbury H 2006. Handbook of Action Research. London: Sage Publications.

Retallick K, Cocklin B, Coombe K 1999. Learning Communities in Education. London: Routledge.
Scott D, Usher R 1999. Researching Education: Data, Methods and Theory in Educational Enquiry. London: Continuum.

Somekh B 2006. Action Research: A Methodology for Change and Development. Maidenhead: Open University Press.

South Africa 1996. The Constitution of the Republic of South Africa Act 108 of 1993. Pretoria: Government Printers.

South Africa 1996. The South African Schools Act 84 of 1996. Pretoria: Government Printers.

Tinning R 2012. Action research as epistemology and practice: Towards transformative. Research in Physical Educ and Sp, 188.

Truman C, Mertens DM, Humphries B 2000. Research and Inequality. London: UCL Press, Taylor and Francis Group.

Walton E, Nel N, Hugo A, Muller H 2009. The extent and practice of inclusion in independent schools in South Africa. South African Journal of Education, 29: 105126.

Weber E 2007. Globalization “global” development and teacher work: A research agenda. Review of Educational Research, 77(3): 279-309.

Yin RK 2012. Case Study Methods. From < Psycnet. apa.org.> (Retrieved on 10 June 2013) 